\title{
Impact of brachytherapy technique (2D versus 3D) on outcomes of cervical cancer: A Systematic Review and Meta-analysis
}

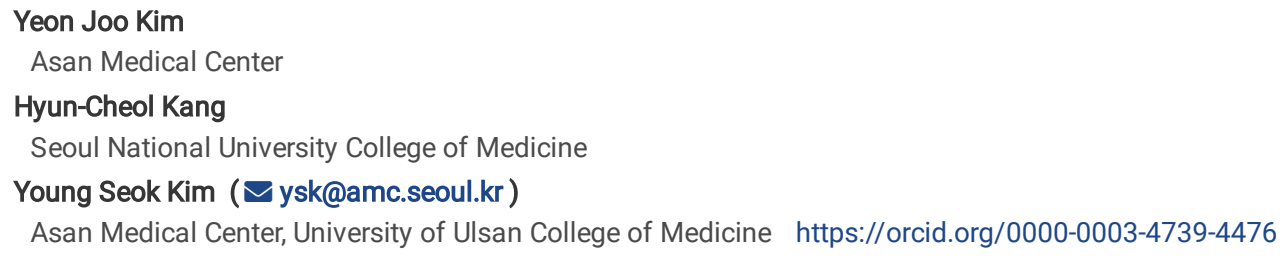

\section{Research}

Keywords: radiotherapy; brachytherapy; uterine cervical neoplasms; toxicity; survival

Posted Date: March 9th, 2020

DOI: https://doi.org/10.21203/rs.3.rs-16273/v1

License: (c) (i) This work is licensed under a Creative Commons Attribution 4.0 International License. Read Full License

Version of Record: A version of this preprint was published at Strahlentherapie und Onkologie on July 6th, 2020. See the published version at https://doi.org/10.1007/s00066-020-01658-0. 


\section{Abstract}

Background: To perform a systematic review and meta-analysis of the impact of brachytherapy (BT) technique (two-dimensional [2D] or three-dimensional image-guided [3D]) on outcomes of cervical cancer patients.

Methods: PubMed and Embase databases were searched up to April 16, 2019, for studies which evaluated the effect of 3D-BT compared to 2D-BT in cervical cancer, and endpoints included cumulative incidence of severe toxicity, locoregional recurrence-free survival (LRRFS), progression-free survival (PFS), and overall survival (OS). Hazard ratios (HRs) were pooled in the meta-analysis using the random-effects model.

Results: Six studies of 8 cohorts were included in the quantitative synthesis. The pooled hazard ratio (HR) regarding toxicity was evaluated in 5 cohorts in 3 studies, and the HR of 3D-BT compared to 2D-BT was 0.54 (95\% confidence interval [Cl], 0.37-0.77). All 6 studies were included for the synthesis for LRRFS, and the pooled HR favors 3D-BT (0.61 [95\% Cl, 0.40-0.93]). For PFS, 3 studies were included for analysis and 3D-BT was superior to 2D-BT (HR $=0.75$ [95\% Cl, 0.0.59-0.96]). Five studies were included for the pooled HR regarding OS, and pooled HR of 3D-BT compared to $2 \mathrm{D}-\mathrm{BT}$ was 0.65 (95\% $\mathrm{Cl}, 0.40-1.06$ ).

Conclusions: 3D-BT might reduce severe toxicity and improve LRRFS, and PFS in patients with cervical cancer. 3D-BT should be considered for standard management of cervical cancer, and efforts for adopting this procedure in Korea should be pursued.

\section{Background}

Brachytherapy (BT) is an essential part of radiotherapy for managing cervical cancer from stage I to IV. BT allows for the delivery of a high dose of radiation to the cervical tumor while sparing the adjacent organs at risk (OAR) due to the steep dose fall-off. For many decades, the standard dosimetric system for BT planning and treatment was based on two-dimensional (2D) orthogonal imaging(1). The prescribed dose of 2D-BT does not adapt to the diverse anatomy and tumor burden of individuals. As result, 2D-BT can lead to overtreatment for patients with small tumors, and undertreatment for those with large tumors. In addition, 2D-BT does not precisely determine the radiation dose for OAR. Grade 3 or 4 toxicity following 2D-BT has been reported to range from 5-30\% for bowel and bladder domains(2-4).

New methods that take advantage of computed tomography (CT) or magnetic resonance imaging (MRI) have been used to develop three-dimensional imageguided BT (3D-BT). In 2005, Groupe Européen de Curiethérapie/European Society for Therapeutic Radiology and Oncology (GEC-ESTRO) published the guideline for 3D-BT(5). GEC-ESTRO evaluated 3D-BT in locally advanced cervical cancer in an international study (Image guided intensity modulated External beam radiochemotherapy and MRI based adaptive BRAchytherapy in locally advanced CErvical cancer, EMBRACE). The EMBRACE I study reported local failure of $6.5 \%$ (crude rate) with median follow-up of 25 months(6). Grade 3 or 4 late rectal morbidity was also limited below $2 \%$ of the patients(7). In addition, a prospective trial comparing 2D-BT and 3D-BT, the French Soutien aux Techniques Innovantes et Coûteuses (STIC), concluded that 3D-BT improved local control with half the toxicity observed with 2D-BT(8).

3D-BT has been broadly adopted in the radiation oncology field for treatment of cervical cancer(9). However, only a limited number of centers perform 3D-BT in Korea, and even more, 2D-BT is only available in $32.5 \%$ of radiation oncology centers(10). Due to the low national health insurance reimbursement, most BT centers suffer a deficit for operating BT, and the proportion of centers offering BT have decreased since 2006. In this circumstance, 3D-BT is difficult to adopt due to the cost. Delays in adopting 3D-BT result in disadvantages for cervical cancer patients who might could benefit from 3D-BT. To foster the wide untilization of 3D-BT in Korea, we performed a systematic review and meta-analysis to evaluate the impact of 3D-BT on toxicity and survivals compared to those of 2D-BT in cervical cancer patients.

\section{Methods}

The present systematic review and meta-analysis followed the Preferred Reporting Items for Systematic Reviews and Meta-Analyses (PRISMA) guidelines(11). The research question of the present meta-analysis was as below: "Would 3D-BT reduce severe toxicity and improve survival outcomes compared to those of 2D-BT in patients with cervical cancer?"

\section{Literature search}

PubMed and Embase databases were searched up to April 16, 2019. Search queries included synonyms of "cervical cancer", "brachytherapy", "toxicity", and "survival" as the following (cervical OR cervix) AND (cancer OR carcinoma) AND (3D OR "image guided" OR image-guided OR adaptive OR 2D OR conventional) AND BT AND (toxicity OR morbidity OR survival OR control). There was no language restriction. The references of retrieved articles were also checked to search the additional relevant studies.

The inclusion criteria was based on the Patient/Intervention/Comparator/Outcome/Study design (PICOS) criteria (11): (1) "patients" with cervical cancer; (2) 3D-BT as the "intervention"; (3) 2D-BT as the "comparator"; (4) cumulative incidence of severe toxicity ( $\geq$ grade 3 ), locoregional recurrence-free survival (LRRFS), progression-free survival (PFS), and overall survival (OS) as "outcome"; and (5) "study design" as original articles or brief report. The exclusion criteria were as follows: (1) not in the field of interest, (2) containing information on single BT technique, and (3) planning study without clinical information.

\section{Data extraction and quality assessment}

A standardized form was used to extract (1) study characteristics including first author, year of publication, institution, period of enrollment, study design (prospective or retrospective/consecutive enrollment), number of groups, and number of patients; (2) clinicopathological characteristics including age, 
pathology, stage, toxicity scoring system, and follow-up period; and (3) treatment characteristics including aim of radiotherapy (definitive or perioperative), rate of concurrent chemotherapy, dose/technique of external beam radiotherapy (EBRT), modality of 3D image guidance, use of interstitial BT, and rate/dose of BT. If published articles did not provide data for quantitative analyses, we contacted to the authors individually.

The methodological quality of included studies was assessed using the Quality in Prognostic Studies (QUIPS) tool(12). Two independent reviewers performed literature selection, data extraction, and quality assessment. If there was any discrepancy, it was resolved via discussion.

\section{Statistical Analysis}

The endpoints were cumulative incidence of severe toxicity, LRRFS, PFS, and OS. Severe toxicity was defined as an adverse event grade $\geq 3$ using Common Terminology Criteria for Adverse Event (CTCAE) or Radiation Therapy Oncology Group and the European Organization for Research and Treatment of Cancer (RTOG/EORTC) criteria. Locoregional recurrence was defined as any recurrences in the planning target volume. Progression-free survival defined as the first relapse either locoregional or as a distant failure. OS was defined as death from any cause.

Hazard ratios (HRs) were used for comparisons between 2D-BT and 3D-BT. HRs with 95\% confidence intervals (Cls) from univariate Cox regression were extracted. When Kaplan-Meier curves were presented, HRs and their Cls were extracted using Engauge Digitizer version 10.4 (http://markummitchell.github.io/engauge-digitizer/) and methodology by Tierney et al.(13).

The HRs were pooled using the random-effects model. Heterogeneity was evaluated with Higgins $I^{2}(14)$ and Cochran's Q(15). The power of the Cochran's Q is low in some circumstances such as small numbers of included studies, so that cut-off for the p-value is 0.1 , not 0.05(16). Funnel plots and Egger's test were performed to assess publication bias(17). Statistical analyses were done using "metafor" package in R (R Foundation for Statistical Computing, version 3.4.3). P-values $<0.05$ were considered statistically significant.

\section{Results}

\section{Study characteristics}

Figure 1 describes the study selection process. The initial literature search retrieved 1410 articles, of which 12 articles were considered potentially eligible. After full-text review, six articles were excluded as they described planning studies without clinical data. Ultimately, six original articles were included(8, 1822). Study characteristics, clinicopathological factors, and treatment are summarized in Tables 1 and 2. The sole prospective study by Charra-Brunaud et al. included three different groups and reported results from each; we pooled their results separately in all analyses(8). Lin et al. compared 2D-EBRT/2D-BT and intensity modulated radiotherapy (IMRT)/3D-BT(22).We included these results in the meta-analysis, but not that 8\% of the patients in the IMRT/3D-BT arm actually received 2D-BT with IMRT. Derks et al. divided patients who underwent 3D-BT into separate cohorts: with and without interstitial needles(21). As the majority of patients included in the other 5 studies did not use needles for 3D-BT, we included the cohort without needles for 3D-BT arm ( $\mathrm{n}=60$ ). The median age was early fifties (range, 47-68). The majority of patients had squamous cell carcinoma at stages I-III. The shortest follow-up period was about 24 months in two studies $(8,20)$, while the others reported follow-up time over 44 months. The aim of treatment was mostly definitive, and rate of concurrent chemotherapy varied. EBRT dose was 45-50.4 Gy in 23-28 fractions, and 2D/3D conformal/IMRT techniques were used. Extended field radiotherapy covering the para-aortic area was also performed for selected patients according to the study protocol. MRI was more commonly used for imaging than CT for 3D-BT. 
Table 1

Study and clinicopathological characteristics of studies included in meta-analysis.

\begin{tabular}{|c|c|c|c|c|c|c|c|c|c|c|c|}
\hline \multicolumn{7}{|c|}{ Study characteristics } & \multicolumn{5}{|c|}{ Clinicopathological characteristics } \\
\hline $\begin{array}{l}\text { First } \\
\text { author }\end{array}$ & Year & Institution & $\begin{array}{l}\text { Enrollment } \\
\text { period }\end{array}$ & $\begin{array}{l}\text { Study } \\
\text { design }\end{array}$ & $\begin{array}{l}\text { No. of } \\
\text { group(s) }\end{array}$ & $\begin{array}{l}\text { No. of } \\
\text { patients }\end{array}$ & $\begin{array}{l}\text { Median } \\
\text { age } \\
\text { (year) }\end{array}$ & $\begin{array}{l}\text { Pathology, } \\
\text { SqCC (\%) }\end{array}$ & $\begin{array}{l}\text { FIGO Stage } \\
(\%) \\
\text { I/II/III/IV }\end{array}$ & $\begin{array}{l}\text { Toxicity } \\
\text { scoring } \\
\text { system }\end{array}$ & $\begin{array}{l}\text { Median } \\
\text { follow- } \\
\text { up } \\
\text { (months) }\end{array}$ \\
\hline $\begin{array}{l}\text { Kang } \\
{[18]}\end{array}$ & 2010 & $\begin{array}{l}\text { National } \\
\text { Cancer } \\
\text { Center, South } \\
\text { Korea }\end{array}$ & $\begin{array}{l}2001- \\
2005\end{array}$ & $\mathrm{R}$ & 1 & 230 & 58 & 90 & $16 / 63 / 16 / 5$ & RTOG/EORTC & 50 \\
\hline \multirow[t]{3}{*}{$\begin{array}{l}\text { Charra- } \\
\text { Brunaud } \\
\text { [8] }\end{array}$} & \multirow[t]{3}{*}{2012} & \multirow[t]{3}{*}{$\begin{array}{l}\text { Multicenter, } \\
\text { France }\end{array}$} & \multirow[t]{3}{*}{$\begin{array}{l}2005- \\
2007\end{array}$} & \multirow[t]{3}{*}{$\mathrm{P}$} & 1 & 165 & $\begin{array}{l}48 / 47^{a} \\
(2 D / 3 D)\end{array}$ & 67 & $90 / 10 / 0 / 0$ & \multirow[t]{3}{*}{ CTCAE 3.0} & \multirow[t]{3}{*}{24.3} \\
\hline & & & & & 2 & 305 & $49 / 48^{a}$ & 80 & $10 / 80 / 10 / 0$ & & \\
\hline & & & & & 3 & 235 & $56 / 53^{a}$ & 67 & $7 / 63 / 30 / 0$ & & \\
\hline $\begin{array}{l}\text { Rijkmans } \\
\text { [19] }\end{array}$ & 2014 & $\begin{array}{l}\text { Leiden } \\
\text { University } \\
\text { Medical } \\
\text { Center, } \\
\text { Netherlands }\end{array}$ & $\begin{array}{l}2000- \\
2012\end{array}$ & $\mathrm{R}$ & 1 & 126 & 56 & 80 & $\begin{array}{l}\text { 19/58/23(III- } \\
\text { IV) }\end{array}$ & CTCAE 3.0 & 45.3 \\
\hline $\begin{array}{l}\text { Thomas } \\
\text { [20] }\end{array}$ & 2017 & $\begin{array}{l}\text { University of } \\
\text { Texas } \\
\text { Southwestern } \\
\text { Medical } \\
\text { Center, USA }\end{array}$ & $\begin{array}{l}2009- \\
2014\end{array}$ & $\mathrm{R}$ & 1 & 71 & NR & NR & $32 / 41 / 24 / 3$ & CTCAE 4.0 & $\begin{array}{l}\text { NR } \\
\text { (reported } \\
\text { 2-year } \\
\text { survival) }\end{array}$ \\
\hline $\begin{array}{l}\text { Derks } \\
{[21]}\end{array}$ & 2018 & $\begin{array}{l}\text { Catharina } \\
\text { Hospital, } \\
\text { Netherlands }\end{array}$ & $\begin{array}{l}1997- \\
2009\end{array}$ & $\mathrm{R}$ & 1 & 126 & $\begin{array}{l}68 / 50 \\
(2 D / 3 D)\end{array}$ & 85 & $\begin{array}{l}26 / 53 / 21 \text { (III- } \\
\text { IV) }\end{array}$ & CTCAE 4.03 & $\begin{array}{l}44 / 50 \\
(2 D / 3 D)\end{array}$ \\
\hline Lin [22] & 2019 & $\begin{array}{l}\text { Washington } \\
\text { University } \\
\text { School of } \\
\text { Medicine, } \\
\text { USA }\end{array}$ & $\begin{array}{l}1997- \\
2013\end{array}$ & $\mathrm{R}$ & 1 & 600 & 50 & 86 & $33 / 41 / 25 / 1$ & CTCAE 3.0 & 127.2 \\
\hline \multicolumn{12}{|c|}{$\begin{array}{l}\text { 2D, two-dimensional; 3D, three-dimensional; CTCAE, Common Terminology Criteria for Adverse Events; FIGO, The International Federation of Gynecology } \\
\text { and Obstetrics; LRFS, local recurrence-free survival; LRRFS, locoregional recurrence-free survival; No., number; NR, not reported; OS, overall survival; P, } \\
\text { prospective; PFS, progression-free survival; R, retrospective; RT, radiotherapy; RTOG/EORTC, Radiation Therapy Oncology Group (RTOG) and the European } \\
\text { Organization for Research and Treatment of Cancer (EORTC); SqCC, squamous cell carcinoma; USA, United States of America }\end{array}$} \\
\hline
\end{tabular}


Table 2

Characteristics of treatment

\begin{tabular}{|c|c|c|c|c|c|c|c|c|c|}
\hline $\begin{array}{l}\text { First } \\
\text { author }\end{array}$ & $\begin{array}{l}\text { Aim of } \\
\text { treatment }\end{array}$ & $\begin{array}{l}\text { Rate of } \\
\text { CCRT } \\
(\%)\end{array}$ & $\begin{array}{l}\text { EBRT } \\
\text { dose } \\
(\mathrm{Gy} / \mathrm{fx})\end{array}$ & $\begin{array}{l}\text { EBRT } \\
\text { technique }\end{array}$ & $\begin{array}{l}\text { Rate of } \\
\text { EFRT } \\
(\%)\end{array}$ & $\begin{array}{l}\text { Method of } \\
\text { image } \\
\text { guidance }\end{array}$ & $\begin{array}{l}\text { Use of } \\
\text { interstitial } \\
\text { needles }(\%)^{c}\end{array}$ & $\begin{array}{l}\text { Dose } \\
\text { rate of } \\
\text { BT }\end{array}$ & Dose of BT \\
\hline Kang [18] & Definitive & 86 & $45 / 25$ & $\begin{array}{l}\text { 2D or 3D } \\
\text { conformal }\end{array}$ & 8 & MRI 100\% & 0 & HDR & $\begin{array}{l}\text { Median total dose to } \\
\text { point } A, E Q D_{2} 10 G y \\
82.1 / 81.8(2 D / 3 D)\end{array}$ \\
\hline \multirow[t]{3}{*}{$\begin{array}{l}\text { Charra- } \\
\text { Brunaud } \\
{[8]}\end{array}$} & Postoperative & 1 & $\begin{array}{l}\text { Not } \\
\text { performed }\end{array}$ & 4 -field ${ }^{b}$ & 0 & $\begin{array}{l}\text { MRI 18\%, CT } \\
82 \%\end{array}$ & 0 & $\begin{array}{l}\text { LDR or } \\
\text { PDR }\end{array}$ & $\begin{array}{l}\text { Mean total dose to } \\
\text { point A, Gy } \\
61.4 / 64.7(2 \mathrm{D} / 3 \mathrm{D})\end{array}$ \\
\hline & Preoperative & 94 & $45 / 25$ & & 7 & & 0 & $\begin{array}{l}\text { LDR or } \\
\text { PDR }\end{array}$ & $64.7 / 62.6$ \\
\hline & Definitive & 84 & $45 / 25$ & & 22 & & 0 & $\begin{array}{l}\text { LDR or } \\
\text { PDR }\end{array}$ & $68.5 / 70.8$ \\
\hline $\begin{array}{l}\text { Rijkmans } \\
\text { [19] }\end{array}$ & Definitive & 52 & $\begin{array}{l}45- \\
50.4 / 23- \\
28\end{array}$ & $\begin{array}{l}\text { 2D or 3D } \\
\text { conformal }\end{array}$ & NR & $\begin{array}{l}\text { MRI } 87 \%, \text { CT } \\
13 \%\end{array}$ & 13 & $\begin{array}{l}\text { LDR or } \\
\text { HDR }\end{array}$ & $\begin{array}{l}\text { Mean BT boost dose to } \\
\text { point A, Gy } \\
27.6 / 20.8 / 20.8 \text { (2D- } \\
\text { LDR/2D-HDR/3D-HDR) }\end{array}$ \\
\hline $\begin{array}{l}\text { Thomas } \\
\text { [20] }\end{array}$ & Definitive & 100 & NR & $\begin{array}{l}\text { 3D } \\
\text { conformal } \\
\text { or IMRT }\end{array}$ & NR & CT $100 \%$ & 0 & HDR & $\begin{array}{l}\text { Mean total dose to } \\
\text { point A, Gy } \\
90 / 80.9(2 D / 3 D)\end{array}$ \\
\hline Derks [21] & Definitive & 73 & $45-50 / 25$ & $\begin{array}{l}\text { 3D } \\
\text { conformal } \\
\text { or IMRT }\end{array}$ & NR & MRI 100\% & $66^{a}$ & HDR & $\begin{array}{l}\text { HR-CTV D90, EQD } 210 \\
\text { Gy } \\
\text { NR/85.3 (2D/3D) }\end{array}$ \\
\hline Lin [22] & Definitive & 89 & $50.4 / 28$ & 2D or IMRT & 15.3 & $\begin{array}{l}\text { MRI 74\%, CT } \\
18 \%\end{array}$ & 0 & $\begin{array}{l}\text { HDR or } \\
\text { LDR }\end{array}$ & $\begin{array}{l}\text { Routine boost dose to } \\
\text { point A, Gy } \\
\text { NR/39/39 (2D-LDR/2D- } \\
\text { HDR/3D-HDR) }\end{array}$ \\
\hline \multicolumn{10}{|c|}{ 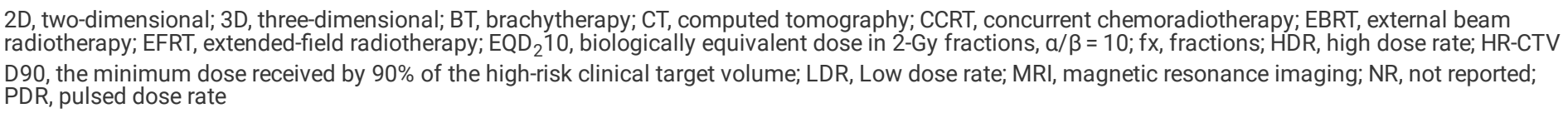 } \\
\hline \multicolumn{10}{|c|}{ 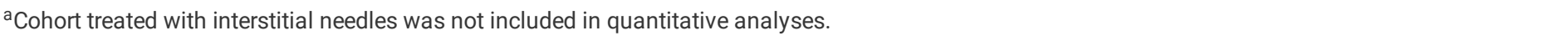 } \\
\hline \multicolumn{10}{|c|}{${ }^{b}$ Did not specify whether they utilized 2D or 3D conformal technique. } \\
\hline
\end{tabular}

There was one study that provided local recurrence-free survival as defined by relapse occurring in primary cervical lesion instead of LRRFS, which also included relapse occurring in nodal area(8), and another study which did not provide clear definition of local control(20). However, both were also included for LRRFS analysis with flexibility. The additional survival outcomes of Kang et al. were obtained by personal communication(18).

\section{Quality assessment}

Figure 2 presents risk of bias assessment using the QUIPS tool. For selection bias, two studies had moderate risk, as the study populations were enrolled retrospectively and did not report consecutive enrollment $(19,21)$. Two trials did not provide drop-out information, so that they had moderate risks of attrition bias $(8,22)$. Regarding prognostic factor measurement, one study had a moderate risk of bias as it did not report continuous variables for age, follow-up time, or information on major clinicopathological factors such as pathology and EBRT dose(20). For outcome measurement, one study had a moderate risk of bias, because of an unclear definition of local control(20). Regarding confounding bias, two studies had a moderate risk as no multivariate analysis was performed $(20,21)$. All the studies had a low risk of statistical analysis bias.

\section{Cumulative incidence of severe toxicity}

The HR of 3D-BT compared to 2D-BT regarding cumulative incidence of $\geq$ grade 3 toxicity was evaluated in 5 cohorts in 3 studies (Fig. $3 a$ ). The other 3 studies were excluded for meta-analysis, since they did not provide time-to-event data; instead, they evaluated the crude incidence rate of severe toxicities after 2D- and 3D-BT. Rijkmans et al. found lower toxicity rates after 3D-BT (7.3\%) compared to 2D-BT (21.4\%, p = 0.04)(19), and Thomas et al. also demonstrated significantly lower gastrointestinal and vaginal ( $\geq$ grade 2 ) toxicity rates in patients who received 3D-BT than in those receiving 2D-BT(20). Derks et al. did not provide P-values, but reported superiority of 3D-BT with respect to toxicity (2D vs. 3D, $17 \%$ vs. $6 \%)(21)$.

The pooled HR significantly favoring 3D-BT compared to $2 \mathrm{D}-\mathrm{BT}$ was $0.54(95 \% \mathrm{Cl}, 0.37-0.77)$. No heterogeneity was present in all subgroup analyses $\left(\mathrm{I}^{2}=0 \%\right)$ and P-value also was not significant $(\mathrm{p}=0.47)$. Publication bias was not definitely present upon visual assessment of the funnel plot $(\mathrm{Fig}$. $4 \mathrm{a})$ and was not significant using Egger's test $(p=0.290)$. 


\section{Locoregional recurrence-free survival}

Eight cohorts in 6 studies were included for the pooled HR for LRRFS (Fig. 3b). The HR of 3D-BT was 0.61 (95\% Cl, 0.40-0.93) compared to 2D-BT. Moderate heterogeneity was found $\left(\mathrm{I}^{2}=45 \%\right)$ and P-value was also 0.08 which represented significant heterogeneity. A funnel plot was provided in Fig. $4 \mathrm{~b}$, and the $\mathrm{P}$ value from the Egger's test was 0.783 , so that there was no significant publication bias.

\section{Progression-free survival}

For the HR regarding PFS according to BT technique, 3 studies were evaluated for meta-analysis (Fig. 3c). Derks et al. did not report PFS(21), and the other two excluded studies did not provide sufficient data $(8,19)$. Charra-Brunaud et al. did not report significantly higher PFS in 3D-BT compared to 2D-BT(8), while Rijkmans et al. reported superior 3-year PFS in 3D-BT (83\%) compared to $2 \mathrm{D}-\mathrm{BT}(49 \%, \mathrm{p}<0.01)(19)$.

The pooled HR of 3D-BT was $0.75(95 \% \mathrm{Cl}, 0.0 .59-0.96)$ compared to $2 \mathrm{D}-\mathrm{BT}$. No heterogeneity was present in the analyses $\left(\mathrm{I}^{2}=0 \%\right)$, and P-value was 0.63 . Funnel plot was demonstrated in Fig. 4c, and p-value of Egger's test was 0.941. Publication bias was not significant.

\section{Overall survival}

The impact of 3D-BT for OS was assessed in 5 studies (Fig. 6). The sole excluded study was Charra-Brunaud et al. because of the paucity of data for metaanalysis; they reported similar OS between 2D-BT and 3D-BT groups $(p=0.27)(8)$.

Pooled HR of 3D-BT compared to 2D-BT was $0.65(95 \% \mathrm{Cl}, 0.40-1.06)$, and moderate heterogeneity was found $\left(\mathrm{I}^{2}=66 \%\right)$. P-value was also significant $(\mathrm{p}=$ 0.02). Visual assessment of the funnel plot was provided in Fig. $4 d$ and $p$-value of Egger's test $(p=0.781)$ showed that there was no significant publication bias.

\section{Discussion}

The present study demonstrated that 3D-BT seemed to reduce severe toxicity and improve LRRFS and PFS for cervical cancer patients when compared to 2DBT with HR of 0.54 (95\% Cl, 0.37-0.77), 0.61 (95\% Cl 0.40-0.93), and 0.75 (95\% Cl 0.59-0.96), respectively. 3D-BT had no impact on OS (HR 0.65, 95\% Cl $0.40-1.06)$.

The effect of 3D-BT was most evident in reducing toxicity. Although half of the six studies were not included for meta-analysis for toxicity, the excluded studies also reported meaningful reductions of $\geq$ grade 3 toxicity in 3D-BT patients. The toxicity outcomes of previous EMBRACE studies evaluating MRI based 3D-BT have shown favorable results. The 2-year actuarial probability of severe vaginal morbidity was $3.6 \%$, which was less than has been reported from earlier studies of $\sim 30 \%(4,23)$. Likewise, late severe rectal toxicities were rare $(1.7 \%)$, and they were strongly related to dosimetric parameters (e.g., $\left.D_{2 \mathrm{~cm}}{ }^{3}\right)$ which available through 3D image guidance(24). The incidence of women diagnosed with cervical cancer in their 20 s has increased from 1993 through 2002(25), and the younger population tends to be more affected by severe toxicity owing to their long life expectancy, so the rapid introduction of 3D-BT should be needed.

LRRFS was also considerably improved with 3D-BT, and this might contribute to the improvement of PFS. These results seem reasonable, since 3D imaging may be more likely to have sufficient radiation dose coverage for primary cervical tumors. The previous RetroEMBACE study also reported excellent 3-year local control of $91 \%$ and pelvic control of $87 \%(26)$. This was $10 \%$ improvement of pelvic control compared to that of a historical $2 \mathrm{D}-\mathrm{BT}$ cohort. A recent EBRACE report also found that nodal failure rate after concurrent chemoradiotherapy and 3D-BT was $11 \%$, with a median follow-up time of 34 months, and one quarter of which were diagnosed with simultaneous local recurrence(27).

The present study failed to show the improvement of OS in patients treated with 3D-BT compared to 2D-BT. However, there should be a group of patients who might have improved OS with 3D-BT, such as patients with bulky primary tumors. The majority of the patients included in the present study utilized intracavitary BT consisted of tandem and ovoid/ring sources. Only a few patients received interstitial BT using needles. The guideline from the American Brachytherapy Society recommends high-dose rate interstitial BT for patients with bulky tumors, a narrow vaginal apex, inaccessible cervical os, tumor invasion to the lateral parametria or pelvic sidewall, and extension to the lower vagina(28). As multiple needle insertions for bulky or advanced tumor are needed, it is more invasive than intracavitary BT, making 3D imaging is essential. Interstitial BT could be more widely utilized, and could lead to improvement of OS.

In addition, $~ 40 \%$ of patients included in the present meta-analysis received CT based 3D-BT. MRI provides superior soft tissue delineation compared with CT, so that there has been a concern that target volume might different between CT and MRI $(29,30)$. A previous planning study compared CT and MRI guided brachytherapy, and resulted in that CT planning may compromise target volume coverage and increase OAR dose (29). Increasing the use of MRI based brachytherapy also could lead the improvement of survival and toxicities.

Use of 3D-BT does carry added cost compared to 2D-BT. Not only costs for cross-sectional imaging, but also additional time, the availability of imaging machines, and longer planning time should be taken into consideration. Therefore, cost-effectiveness could be another issue. A cost-effectiveness analysis performed in the United States using a Markov state transition model based on 3-year survival estimates and severe complication rates from the previous studies concluded that 3D-BT is a cost-effective option compared to 2D-BT, and supporting the routine use of 3D-BT in locally advanced cervical cancer(31). Although the exact costs differ between the United States and Korea, the result suggests that adoption of 3D-BT could save medical costs.

With the growing evidence, 3D-BT is becoming a new standard worldwide. In the United States, there was an increased percentage of using CT for BT from 55-95\%) or MRI for BT from 2-34\% between 2007 and 2014(32). A 2015 survey in Japan found that only 16\% of facilities had adopted 3D-BT, but 53\% of 
facilities had plans to adopt 3D-BT in the future(33). However, adoption of 3D-BT in Korea is limited due to low medical reimbursement(10). Apart from EBRT, $\mathrm{BT}$ is another independent treatment modality which has advantages of rapid dose fall-off around the radioactive sources. There have been attempts to replace the BT boost to EBRT in cervical cancer, but they resulted in worsening of survival by $12 \%(34)$. BT could be applied to other cancers in addition to cervical cancer, such as for malignancies in the prostate, breast, head and neck, respiratory tract, and digestive organs. Re-irradiation also could be performed with escalating doses with BT compared to EBRT.

There were several limitations in this meta-analysis. First of all, a majority of the studies included were retrospective trials, which might lead to an overestimation of pooled HRs. Also, all retrospective studies were limited by shorter follow-up time in 3D-BT patients compared to 2D-BT patients. Furthermore, the number of studies for meta-analysis was small, and due to the lack of provided data, only 3 studies were included for meta-analysis of cumulative incidence of toxicity and PFS. The characteristics were varied among the studies (Tables 1 and 2), and analyses for LRRFS and OS had moderate heterogeneity. Meta-regression analysis could be used to evaluate the impact of these factors; however, it was impossible in the present study due to the limited number of studies and available data. In addition, this was not an individual patient data meta-analysis. Lastly, patients included in the 3D-BT group tended to receive more advanced EBRT techniques such as 3D conformal or IMRT. Although well designed large randomized controlled studies are warranted to confirm the present findings, so far, the present study is the first systematic review and meta-analysis of clinical outcomes of patients with cervical cancer who have received $3 \mathrm{D}-\mathrm{BT}$ or $2 \mathrm{D}-\mathrm{BT}$.

\section{Conclusions}

3D-BT might be a better option for the patients with cervical cancer than 2D-BT in terms of toxicity, LRRFS, and PFS. 3D-BT is becoming the new standard care for cervical cancer, and introduction of 3D-BT is an urgent task for radiation oncology centers in Korea.

\section{Abbreviations}

BT

brachytherapy

$\mathrm{Cl}$

confidence interval

Cls

confidence intervals

CT

computed tomography

CTCAE

Common Terminology Criteria for Adverse Event

\section{EBRT}

external beam radiotherapy

EMBRACE

Image guided intensity modulated External beam radiochemotherapy and MRI based adaptive BRAchytherapy in locally advanced CErvical cancer GEC-ESTRO

Groupe Européen de Curiethérapie/European Society for Therapeutic Radiology and Oncology

HR

hazard ratio

HRs

hazard ratios

IMRT

intensity modulated radiotherapy

LRRFS

locoregional recurrence-free survival

MRI

magnetic resonance imaging

OAR

organs at risk

OS

overall survival

PICOS

Patient/Intervention/Comparator/Outcome/Study

PFS

progression-free survival

PRISMA

Preferred Reporting Items for Systematic Reviews and Meta-Analyses

QUIPS

Quality in Prognostic Studies 


\section{RTOG/EORTC}

Radiation Therapy Oncology Group and the European Organization for Research and Treatment of Cancer

STIC

Soutien aux Techniques Innovantes et Coûteuses

$2 \mathrm{D}$

two-dimensional

3D

three-dimensional image-guided

\section{Declarations}

\section{Ethics approval and consent to participate}

Not applicable.

\section{Consent for publication}

Not applicable.

\section{Availability of data and materials}

The datasets analysed during the current study are available from the corresponding author on reasonable request.

\section{Competing interests}

The authors have no conflict of interest to report.

\section{Funding}

Not applicable.

\section{Author contributions}

YJ Kim and H Kang participated in data acquisition and analysis, literature research and drafting of the manuscript. YS Kim contributed to the conception and design of the study, and revised the manuscript.

\section{Acknowledgments}

Not applicable.

\section{References}

1. Narayan K, Barkati M, van Dyk S, Bernshaw D. Image-guided brachytherapy for cervix cancer: from Manchester to Melbourne. Expert review of anticancer therapy. 2010;10(1):41-6.

2. Roeske JC, Mundt AJ, Halpern H, Sweeney P, Sutton H, Powers C, et al. Late rectal sequelae following definitive radiation therapy for carcinoma of the uterine cervix: A dosimetric analysis. International Journal of Radiation Oncology*Biology*Physics. 1997;37(2):351-8.

3. Perez CA, Grigsby PW, Lockett MA, Chao KSC, Williamson J. Radiation therapy morbidity in carcinoma of the uterine cervix: dosimetric and clinical correlation. International Journal of Radiation Oncology*Biology*Physics. 1999;44(4):855-66.

4. Pötter R, Knocke T, Fellner C, Baldass M, Reinthaller A, Kucera H. Definitive radiotherapy based on HDR brachytherapy with iridium 192 in uterine cervix carcinoma: report on the Vienna University Hospital findings (1993-1997) compared to the preceding period in the context of ICRU 38 recommendations. Cancer/Radiothérapie. 2000;4(2):159-72.

5. Haie-Meder C, Pötter R, Van Limbergen E, Briot E, De Brabandere M, Dimopoulos J, et al. Recommendations from Gynaecological (GYN) GEC-ESTRO

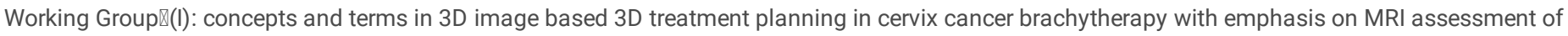
GTV and CTV. Radiotherapy and oncology. 2005;74(3):235-45.

6. Schmid M, Haie-Meder C, Mahanshetty U, Jürgenliemk-Schulz IM, Segedin B, Hoskin P, et al. OC-0055: Local failures after radiochemotherapy and MRimage-guided brachytherapy in cervical cancer patients. Radiotherapy and Oncology. 2017;123:S26.

7. Mazeron R, Fokdal LU, Kirchheiner K, Georg P, Jastaniyah N, Segedin B, et al. Dose-volume effect relationships for late rectal morbidity in patients treated with chemoradiation and MRI-guided adaptive brachytherapy for locally advanced cervical cancer: Results from the prospective multicenter EMBRACE study. Radiotherapy and oncology : journal of the European Society for Therapeutic Radiology and Oncology. 2016;120(3):412-9.

8. Charra-Brunaud C, Harter V, Delannes M, Haie-Meder C, Quetin P, Kerr C, et al. Impact of 3D image-based PDR brachytherapy on outcome of patients treated for cervix carcinoma in France: results of the French STIC prospective study. Radiotherapy and oncology : journal of the European Society for Therapeutic Radiology and Oncology. 2012;103(3):305-13.

9. Cho 0, Chun M. Management for locally advanced cervical cancer: new trends and controversial issues. Radiation oncology journal. 2018;36(4):254-64. 
10. Kim H, Kim JY, Kim J, Park W, Kim YS, Kim HJ, et al. Current status of brachytherapy in Korea: a national survey of radiation oncologists. J Gynecol Oncol. 2016;27(4):e33-e.

11. Liberati A, Altman DG, Tetzlaff J, Mulrow C, Gotzsche PC, loannidis JP, et al. The PRISMA statement for reporting systematic reviews and meta-analyses of studies that evaluate health care interventions: explanation and elaboration. Journal of clinical epidemiology. 2009;62(10):e1-34.

12. Hayden JA, van der Windt DA, Cartwright JL, Cote P, Bombardier C. Assessing bias in studies of prognostic factors. Annals of internal medicine. 2013;158(4):280-6.

13. Tierney JF, Stewart LA, Ghersi D, Burdett S, Sydes MR. Practical methods for incorporating summary time-to-event data into meta-analysis. Trials. 2007;8:16.

14. Higgins JP, Thompson SG, Deeks JJ, Altman DG. Measuring inconsistency in meta-analyses. BMJ (Clinical research ed). 2003;327(7414):557-60.

15. Cochran WG. The combination of estimates from different experiments. Biometrics. 1954;10(1):101-29.

16. Fleiss JL. Analysis of data from multiclinic trials. Controlled clinical trials. 1986;7(4):267-75.

17. Egger M, Davey Smith G, Schneider M, Minder C. Bias in meta-analysis detected by a simple, graphical test. BMJ (Clinical research ed). 1997;315(7109):629-34.

18. Kang HC, Shin KH, Park SY, Kim JY. 3D CT-based high-dose-rate brachytherapy for cervical cancer: clinical impact on late rectal bleeding and local control. Radiotherapy and oncology : journal of the European Society for Therapeutic Radiology and Oncology. 2010;97(3):507-13.

19. Rijkmans EC, Nout RA, Rutten IHHM, Ketelaars M, Neelis KJ, Laman MS, et al. Improved survival of patients with cervical cancer treated with image-guided brachytherapy compared with conventional brachytherapy. Gynecologic oncology. 2014;135(2):231-8.

20. Thomas KM, Maquilan G, Stojadinovic S, Medin P, Folkert MR, Albuquerque K. Reduced toxicity with equivalent outcomes using three-dimensional volumetric (3DV) image-based versus nonvolumetric point-based (NV) brachytherapy in a cervical cancer population. Brachytherapy. 2017;16(5):943-8.

21. Derks K, Steenhuijsen JL, van den Berg HA, Houterman S, Cnossen J, van Haaren P, et al. Impact of brachytherapy technique (2D versus 3D) on outcome following radiotherapy of cervical cancer. Journal of contemporary brachytherapy. 2018;10(1):17.

22. Lin AJ, Kidd E, Dehdashti F, Siegel BA, Mutic S, Thaker PH, et al. Intensity modulated radiation therapy and image-guided adapted brachytherapy for cervix cancer. International Journal of Radiation Oncology* Biology* Physics. 2019;103(5):1088-97.

23. Kirchheiner K, Nout RA, Tanderup K, Lindegaard JC, Westerveld H, Haie-Meder C, et al. Manifestation Pattern of Early-Late Vaginal Morbidity After Definitive Radiation (Chemo)Therapy and Image-Guided Adaptive Brachytherapy for Locally Advanced Cervical Cancer: An Analysis From the EMBRACE Study. International Journal of Radiation Oncology*Biology*Physics. 2014;89(1):88-95.

24. Mazeron R, Fokdal LU, Kirchheiner K, Georg P, Jastaniyah N, Šegedin B, et al. Dose-volume effect relationships for late rectal morbidity in patients treated with chemoradiation and MRI-guided adaptive brachytherapy for locally advanced cervical cancer: Results from the prospective multicenter EMBRACE study. Radiotherapy and Oncology. 2016;120(3):412-9.

25. Lim MC, Lee M, Shim SH, Nam EJ, Lee JY, Kim HJ, et al. Practice guidelines for management of cervical cancer in Korea: a Korean Society of Gynecologic Oncology Consensus Statement. J Gynecol Oncol. 2017;28(3).

26. Sturdza A, Pötter R, Fokdal LU, Haie-Meder C, Tan LT, Mazeron R, et al. Image guided brachytherapy in locally advanced cervical cancer: improved pelvic control and survival in RetroEMBRACE, a multicenter cohort study. Radiotherapy and Oncology. 2016;120(3):428-33.

27. Nomden CN, Pötter R, de Leeuw AAC, Tanderup K, Lindegaard JC, Schmid MP, et al. Nodal failure after chemo-radiation and MRI guided brachytherapy in cervical cancer: Patterns of failure in the EMBRACE study cohort. Radiotherapy and Oncology. 2019;134:185-90.

28. Viswanathan AN, Thomadsen B, Committee ABSCCR. American Brachytherapy Society consensus guidelines for locally advanced carcinoma of the cervix. Part I: general principles. Brachytherapy. 2012;11(1):33-46.

29. Yip WWL, Wong JSY, Lee VWY, Wong FCS, Tung SY. Throwing the dart blind-folded: comparison of computed tomography versus magnetic resonance imaging-guided brachytherapy for cervical cancer with regard to dose received by the 'actual' targets and organs at risk. J Contemp Brachytherapy. 2017;9(5):446-52.

30. Koh V, Choo BA, Lee KM, Tan TH, Low JHJ, Ng SYJ, et al. Feasibility study of toxicity outcomes using GEC-ESTRO contouring guidelines on CT based instead of MRI-based planning in locally advanced cervical cancer patients. Brachytherapy. 2017;16(1):126-32.

31. Kim H, Rajagopalan MS, Beriwal S, Huq MS, Smith KJ. Cost-effectiveness analysis of 3D image-guided brachytherapy compared with 2D brachytherapy in the treatment of locally advanced cervical cancer. Brachytherapy. 2015;14(1):29-36.

32. Grover S, Harkenrider MM, Cho LP, Erickson B, Small C, Small W, et al. Image Guided Cervical Brachytherapy: 2014 Survey of the American Brachytherapy Society. International Journal of Radiation Oncology*Biology*Physics. 2016;94(3):598-604.

33. Ohno T, Toita T, Tsujino K, Uchida N, Hatano K, Nishimura T, et al. A questionnaire-based survey on 3D image-guided brachytherapy for cervical cancer in Japan: advances and obstacles. J Radiat Res. 2015;56(6):897-903.

34. Han K, Milosevic M, Fyles A, Pintilie M, Viswanathan AN. Trends in the Utilization of Brachytherapy in Cervical Cancer in the United States. International Journal of Radiation Oncology*Biology*Physics. 2013;87(1):111-9.

\section{Figures}




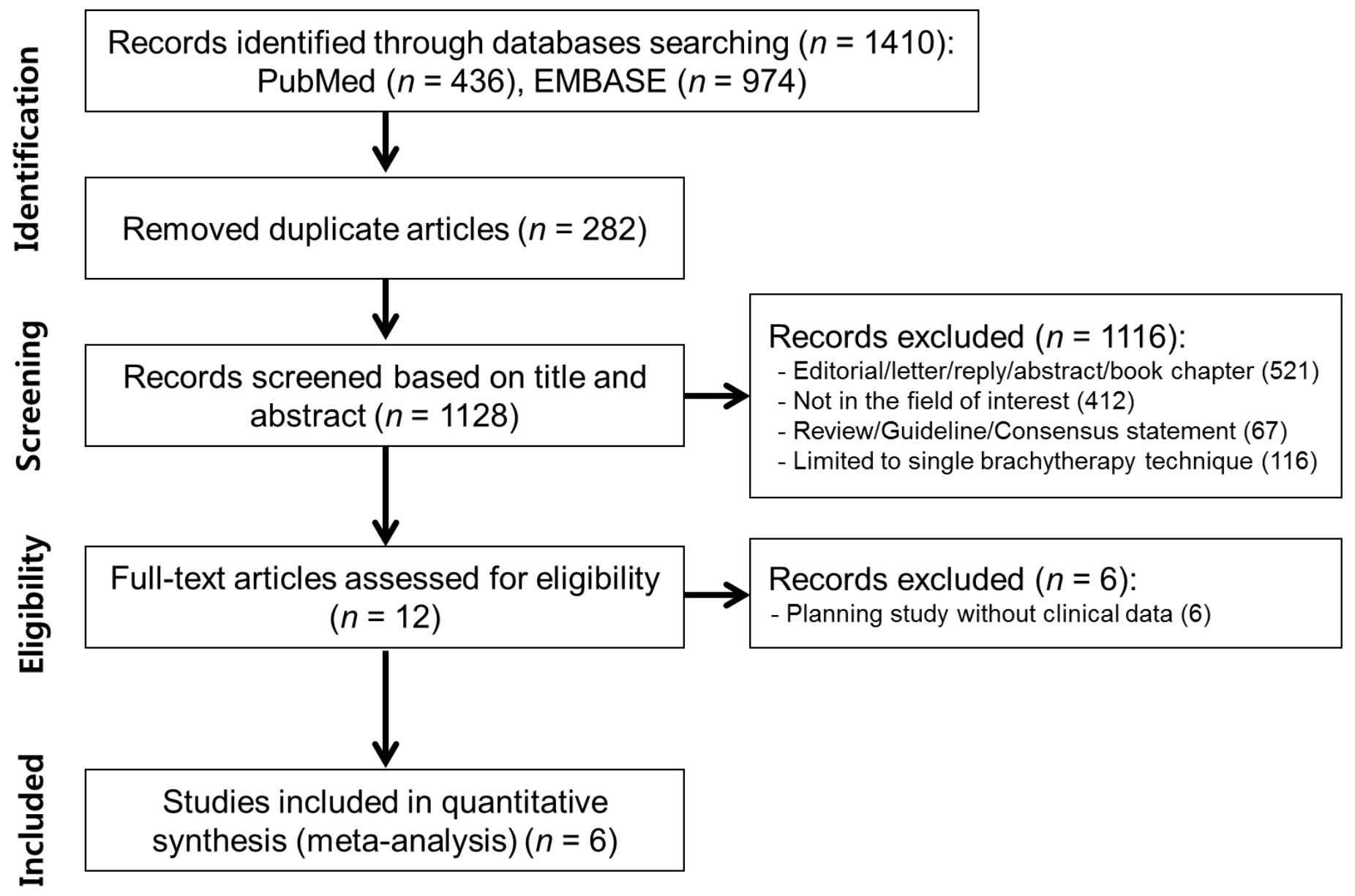

Figure 1

Flow diagram showing the study selection process. 


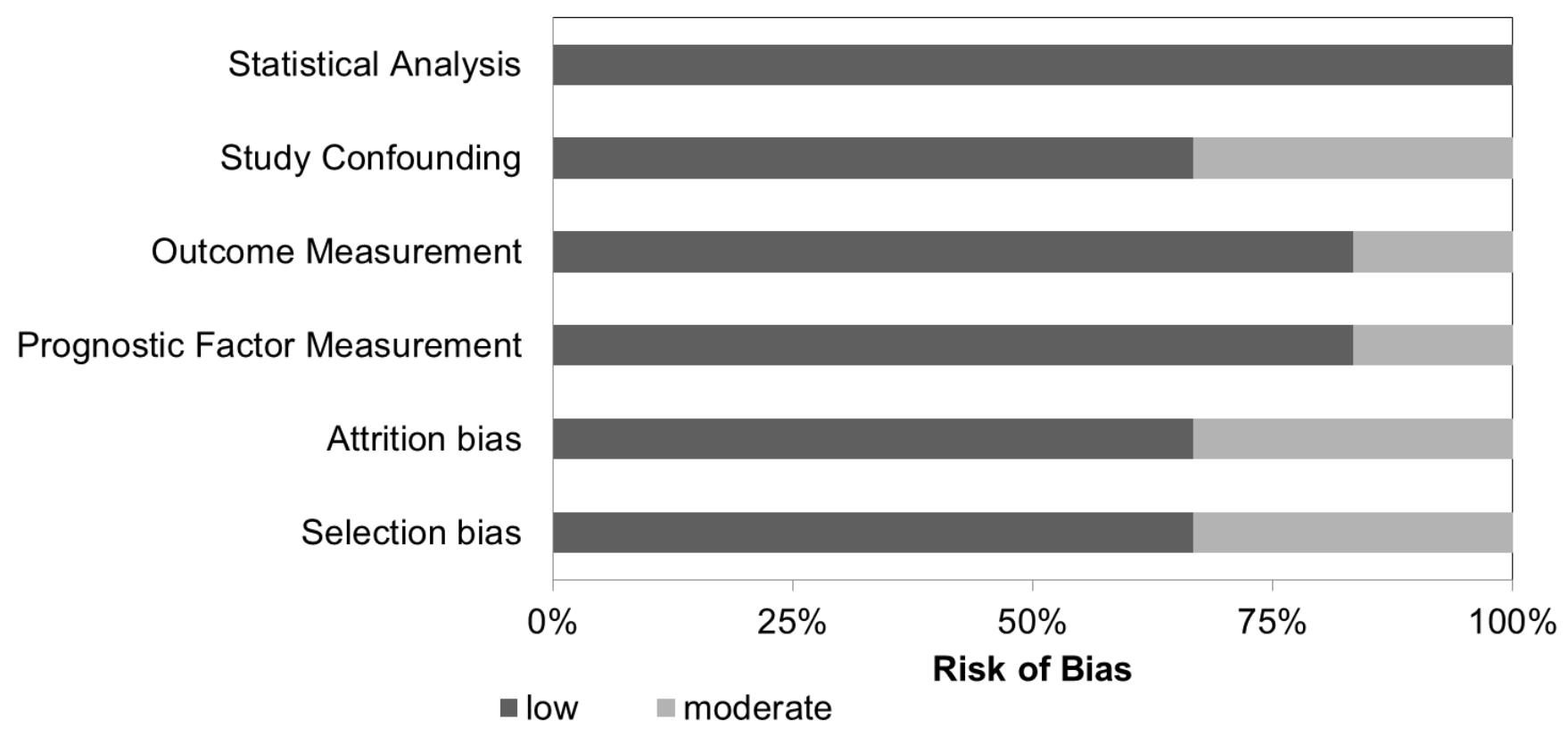

Figure 2

Assessment of risk of bias using the Quality in Prognostic Studies (QUIPS) tool. 
a.

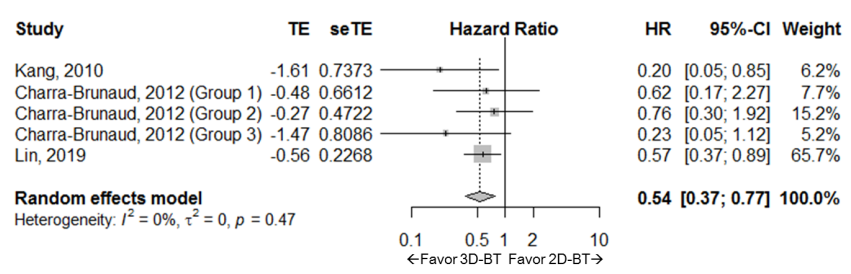

b.

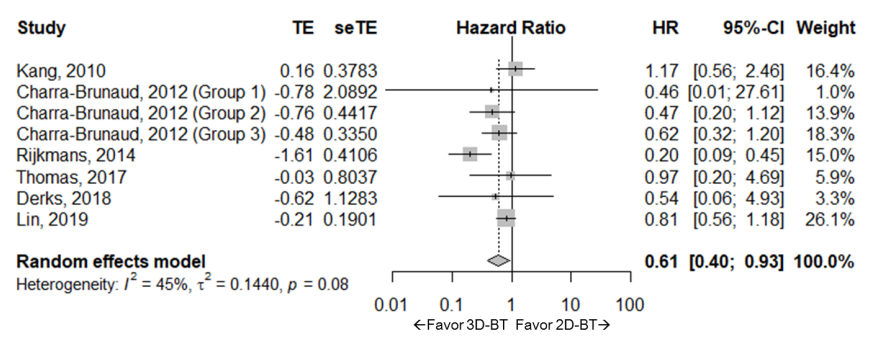

c.

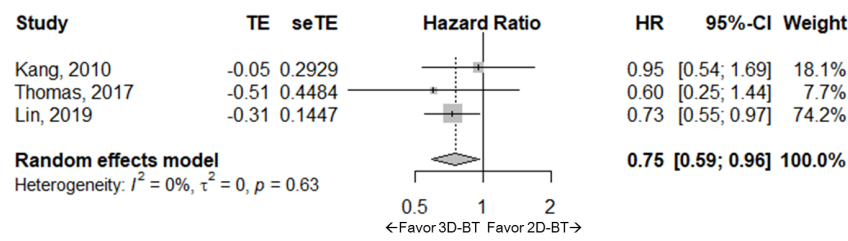

d.

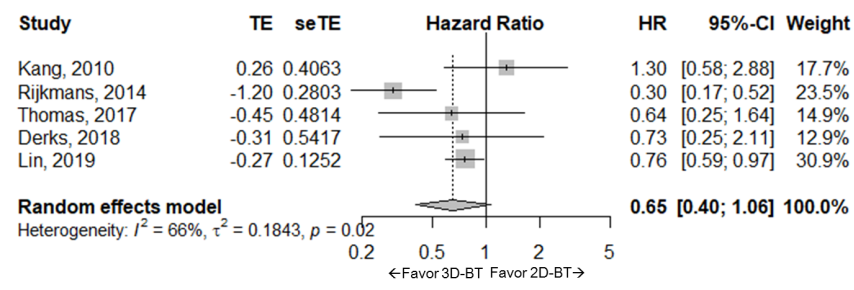

\section{Figure 3}

Forest plots for hazard ratios comparing 3D-brachytherapy (3D-BT) to 2D-brachytherapy (2D-BT) regarding (a) cumulative incidence of severe toxicity, (b) locoregional recurrence-free survival, (c) progression-free survival, (d) and overall survival.

a.

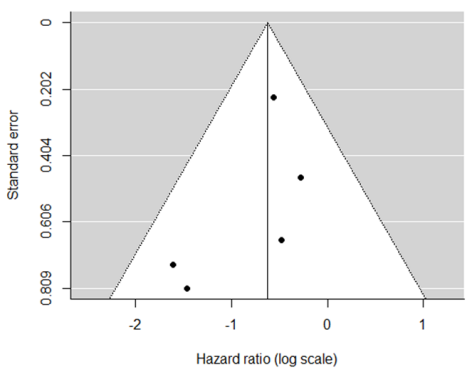

b.

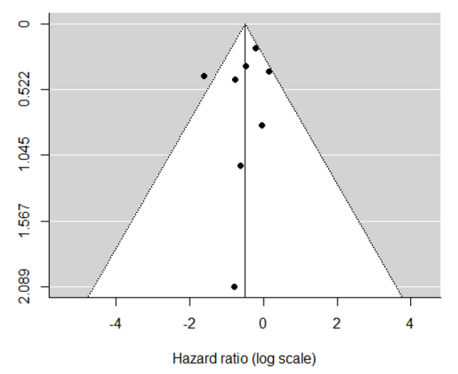

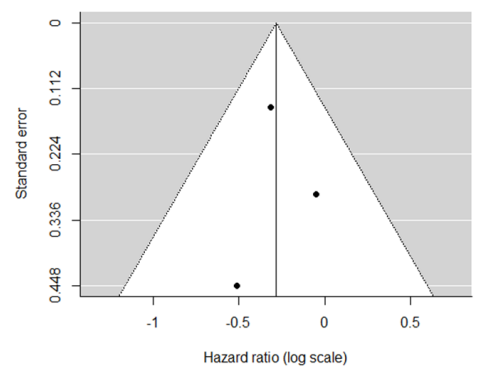

d.

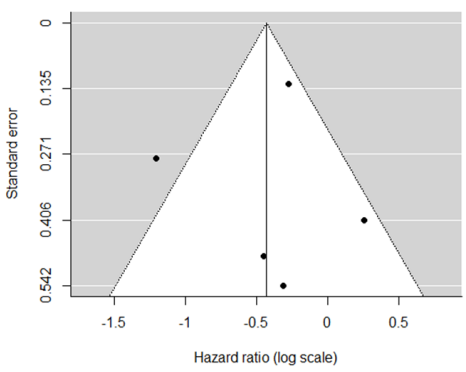

Figure 4

Funnel plots representing hazard ratios of brachytherapy technique (3D versus 2D) regarding (a) cumulative incidence of severe toxicity, (b) locoregional recurrence-free survival, (c) progression-free survival, (d) and overall survival. 